\title{
Gradhiva
}

GRADHIV

Revue d'anthropologie et d'histoire des arts

$10 \mid 2009$

Présence africaine

\section{Extraits d'Histoire d'autres de Georges Balandier}

\section{(2) OpenEdition}

Journals

Édition électronique

URL : http://journals.openedition.org/gradhiva/1575

DOI : 10.4000/gradhiva.1575

ISSN : 1760-849X

Éditeur

Musée du quai Branly Jacques Chirac

Édition imprimée

Date de publication : 4 novembre 2009

Pagination : 170-173

ISBN : 978-2-35744-012-8

ISSN : 0764-8928

Référence électronique

"Extraits d'Histoire d'autres de Georges Balandier », Gradhiva [En ligne], 10 | 2009, mis en ligne le 03 février 2010, consulté le 01 mai 2019. URL : http://journals.openedition.org/gradhiva/1575 ; DOI :

10.4000/gradhiva. 1575

(c) musée du quai Branly 


\section{Georges Balandier Histoire d'autres* (extraits)}

Mon installation [...] incitait au désenchantement; dans l'immeuble « néo-colonial » assez laid que l'I.F.A.N. occupait, je reçus pour logement un réduit en sous-sol. Cette pièce était sinistre et incommode. Alioune Diop, qui devint le fondateur de Présence Africaine, me sortit de cette situation déprimante. Je l'avais rencontré auparavant à Paris, chez les Leiris; il occupait maintenant le poste de chef de cabinet du gouverneur général, Barthes, un haut fonctionnaire libéral, et il disposait d'une grande villa "de fonction». Il me proposa de m'établir chez lui, ainsi que Paul Mercier qui venait d'arriver à Dakar. Ce fut l'origine d'une amitié forte avec luimême et sa femme, Christiane; et aussi l'occasion d'un étonnement - au sens étymologique du mot - de la société blanche coloniale. Alioune et moi, chacun à notre manière, nous avons franchi la ligne. Le temps passé ensemble me fut doux. Tout m'attirait en lui, son élégance naturelle, sa générosité, sa double culture, sa volonté patiente qui ne redoutait ni les obstacles ni les défis : être catholique bien que fils de lettré musulman, parler à des communautés séparées par les différences, l'inégalité et les discriminations. Nous avons discuté, chaque soir, et il fut ainsi mon instituteur. Des visiteurs venaient, des notables, des imams dakarois, des politiciens locaux donc le socialiste Lamine Guèye, des hommes de culture. Je fis la connaissance de Léopold Sédar Senghor. Il m'impressionna, et j'étais d'autant plus sensible à ses propos que j'avais lu ses écrits. Il disait son enfance sérère et l'éducation donnée par son oncle Waly; il évoquait la formation catholique reçue à partir de l'âge de huit ans, et ses premières révoltes; il était discret sur ses brillantes performances universitaires. Mais je connaissais ses succès, et je voyais en lui le professeur et l'écrivain sans percevoir clairement son destin politique. Il est vrai que Senghor a toujours exalté la fonction d'enseignement, il me le rappelait encore à l'occasion d'une visite récente. Il voyait la principale révolution africaine sous la forme d'une révolution culturelle. Et c'est dans ce sens que nous avons orienté nos réflexions, lorsque Diop et quelques amis envisagèrent de créer une revue qui donnerait une voix aux civilisations de l'Afrique; elle se fit un peu plus tard, à Paris, avec un titre suggéré par Sartre qui demandait d'affirmer la présence africaine.

Entre-temps, Alioune, devenu parlementaire, avait dû partir. Il avait pu néanmoins me révéler une Afrique autre que celle qui m’avait été enseignée par les maîtres ès sociétés primitives. Celle du mouvement, des revendications et des créations. La relation pédagogique se renversait, j'étais venu pour observer et je me retrouvais élève. J'ai appris, de tous : de mon entourage africain, des instituteurs formés à l'école normale de Sébikotane et notamment du romancier Abdoulaye Sadji, et surtout des pêcheurs lébous parmi lesquels j'effectuai ma première recherche « de terrain» (Histoire d'autres : 51-52).

J'avais en ce domaine une certaine avance, mon éloignement africain m'ayant empêché de prendre le chemin suivi par mes camarades. Il m'avait entraîné vers une école plus inattendue, lancé dans des expériences fort différentes, dont celle de l'engagement au service d'une revue qui n'était comparable à aucune des autres : c'est Présence Africaine, conçue à Dakar chez Alioune Diop, née à Paris en 1947. Je fus associé à sa conception, j'y travaillai à temps partiel lors de mes séjours parisiens, j'en devins rédacteur en chef avec l'écrivain ivoirien Bernard Dadié pendant un couple d'années. Son "patronage» mêlait l'éclectisme et la célébrité. Il rassemblait la plupart des intellectuels, noirs et blancs, pour lesquels j'avais de l'amitié ou de l'estime. Il m'apporta l'occasion de rencontres nouvelles. Celle de Richard Wright, le roman- 
cier américain qui venait de publier la traduction française de Native Son; colosse noir ayant encore une allure de G.I., dont la force, l'aptitude au bonheur et au plaisir, la voix puissante m'impressionnaient. Il était un exilé du racisme américain, il le resta jusqu'à sa mort; et sa fille, parce qu'elle avait choisi de retourner aux sources nègres de la culture, fut un temps mon étudiante. Emmanuel Mounier était l'un de ceux qui introduisaient la note chrétienne dans le groupe et le témoignage de la critique personnaliste appliquée au colonialisme. Je le rencontrai peu avant sa disparition brutale; silhouette professorale, visage marqué par une participation tragique à la peine des déshérités, porteur d'une exigence de justice et de charité intransigeante, il pouvait apparaître comme une incarnation moderne de la «belle âme ».

La revue vivait chichement et était installée petitement, ce qui nous rassemblait autour d'Alioune. J'aimais m'y rendre. C'était alors rue Henri-Barbusse, au 16, dans l'une des vieilles maisons qui supportent bien la décrépitude. Elle occupait deux pièces sous-louées dans un appartement dont la locataire était une jeune femme fantasque, fort libre de mœurs, entourée d'une cour changeante qui campait parfois dans l'antichambre. Peau blanche, pudeur noire, cette topographie inattendue déconcertait certains visiteurs. La revue se tenait à l'écart, derrière une frontière invisible mais étanche. C'était une sorte d'artisanat familial; des parents et des amis, dont un jeune professeur romancier, Jacques Howlett, qui a prolongé sa fidélité au long des décennies. De temps en temps, David Diop (qu'une mort tragique emporta tôt) faisait surgir sa beauté et son cri de poète : «Souffre, pauvre nègre... » En cette période de commencement, il fallait de l'invention pour imposer le style de la nouvelle publication, de la passion pour le faire vivre, de l'entêtement pour vaincre les difficultés d'édition. Lentement la présence africaine s'affirmait, ce n'était plus l'absence et le silence. Ce fut une révolution culturelle; inconnue, méconnue des critiques fougueux qui partirent ensuite en bataille. L'Europe était contrainte d'entendre ce qu'elle avait fait taire, de voir ce qu'elle s'était caché : un monde noir riche de sa diversité, un nègre «mythifié » et mystifié, un travailleur africain écrasé, un art noir ouvrant les portes de l'imaginaire verrouillées par la raison raisonnable... ces débuts étaient offensifs. La culture qui vit ne se laisse jamais faire. Sur une idée d'Alain Resnais et Chris Marker, la revue entreprit la production d'un film provoquant l'irruption des arts nègres. J'ai travaillé à la préparation de l'argument, de l'iconographie. Après bien des péripéties, il sortit sous un titre qui surprit : Les Statues meurent aussi. Il inquiéta, choqua, et n'obtint pas le visa de censure. La pellicule a pâli; la qualité critique est éventée, mais il n'en avait pas moins été démontré que l'art est politique.

Ces années-là furent pour nous celles de la «négritude ». L'idée et le terme venaient d'avant, de l'avant-guerre, lorsqu'un petit groupe d'Africains et d'Antillais publiait épisodiquement les cahiers de L'Étudiant noir. Césaire pouvait proclamer que sa négritude «est une tour », et Senghor que «l'émotion est nègre", ce n'était pas encore une doctrine. Elle reçut cette promotion de l'art de Sartre qui lui consacra l'un des ses plus grands textes : "Orphée noir ", préface à une anthologie de poètes d'expression française. La négritude était dévoilée : refus, rupture, négation du blanchiment culturel et politique, premières réappropriations des manières d'être, de sentir, de faire et dire reçues de l'héritage nègre. Elle devait, comme le suggérait Sartre, se transformer en «une Passion ». Elle le fut pour quelques-uns, en faisant flamber les débats, ceux qui firent apparaître un jeune médecin originaire de la Martinique, Frantz Fanon. Il était ardent avec du charme, venait de pratiquer le mariage des couleurs, portait en lui et avec éclat nos savoirs, et brûlait d'impatience dans les couloirs de l'existentialisme. Il demanda de me voir lorsqu'il eut achevé la rédaction de son livre : Peau noire, masques blancs. Je compris qu'il se sentait piégé, floué. Tous nos entretiens, par la suite, confirmèrent mon impression. Il se découvrait dépossédé, il voulait retrouver «la possession » qui serait la force le poussant plus loin, plus vite. Jusqu'à la révolution algérienne qui fit exploser son lyrisme militant. Voici quelques années, j'ai été ému, et navré, d'avoir à présider l'une des premières thèses qui lui furent consacrées; les Éditions d'État algériennes la publièrent (Histoire d'autres : 158 -161). 


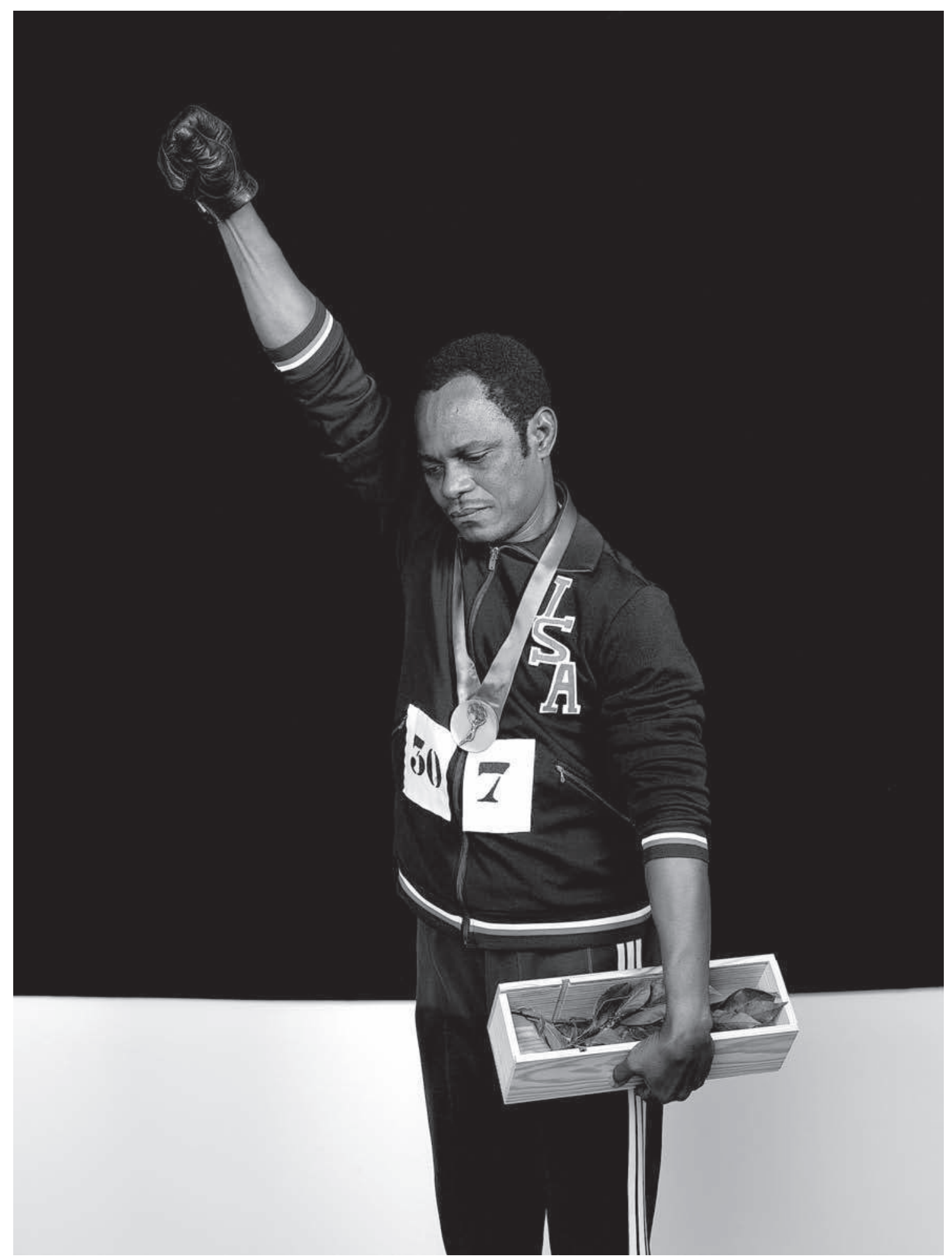

Samuel Fosso, Autoportrait, «African Spirits », L_002649 @ 2009 Samuel Fosso, avec la permission de jean marc patras / galerie / paris. 


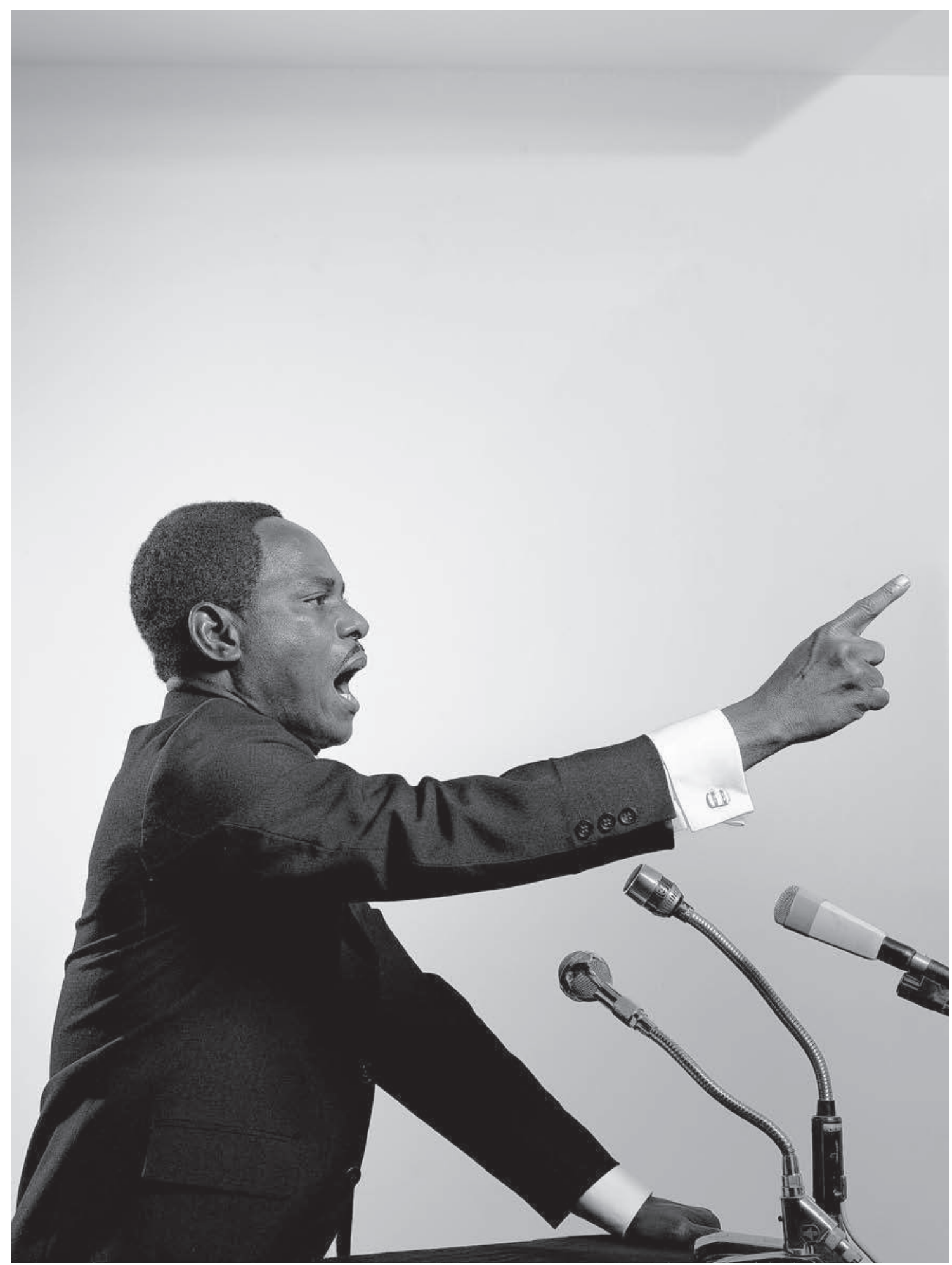

Samuel Fosso, Autoportrait, «African Spirits», L_002802 @ 2009 Samuel Fosso, avec la permission de jean marc patras / galerie / paris. 